\title{
HUBUNGAN EATING DISORDER DENGAN STATUS GIZI PADA REMAJA PUTRI DI MODELING AGENCY SEMARANG.
}

\author{
Aqmariya Syarafina, Enny Probosari ${ }^{*}$ \\ Program Studi Ilmu Gizi Fakultas Kedokteran Universitas Diponegoro \\ Jl.Dr.Sutomo No.18, Semarang, Telp (024) 8453708, Email : gizifk@undip.ac.id
}

\begin{abstract}
ABSTRAK
Latar Belakang : Persepsi body image yang negatif akan mempengaruhi tindakan seseorang untuk melakukan upaya pengurangan konsumsi makan. Keinginan untuk memiliki bentuk tubuh yang sempurna dan persaingan di dunia modeling membuat para model tersebut melakukan perilaku yang tidak tepat dalam mencapai tubuh yang ideal dengan melakukan diet yang terlalu ketat. Diet ketat yang dilakukan para remaja putri dapat berujung pada kebiasaan makan yang kurang baik yang pada akhirnya menyebabkan terjadinya eating disorder sehingga akan berdampak negatif pada status gizi. Penelitian ini bertujuan untuk menganalisis hubungan eating disorder dengan status gizi pada remaja putri.

Metode : Penelitian observasional dengan rancangan cross-sectional bertempat di Modeling Agency Kota Semarang. Sampel berjumlah 59 subjek yang merupakan remaja putri anggota modeling agency usia 15-19 tahun dan dipilih menggunakan metode consecutive sampling. Penilaian status gizi menggunakan persen lemak tubuh dengan Bioelectrical Impedence Analysis (BIA). Penilaian penyimpangan perilaku makan menggunakan kuesioner eating disorder diagnostic scale (EDDS). Data dianalisis menggunakan uji chi square.

Hasil : Sebanyak 40 subjek (67.8\%) mengalami eating disorder dengan 11 subjek (27.5\%) underfat dan 19 subjek (32.2\%) tidak mengalami eating disorder dengan status gizi normal. Terdapat hubungan yang bermakna eating disorder dengan status gizi, nilai $(p=0.01 ; p<0,05)$.

Simpulan : Ada hubungan eating disorder dengan status gizi pada remaja putri.
\end{abstract}

Kata Kunci : Eating disorder; status gizi; agency modeling; remaja putri

\begin{abstract}
ABSTRAK
Background : The negative body image perception can affects a person's actions to undertake efforts to reduce food consumption. The desire to have a perfect body shape and competition in the world of modeling makes the model perform improper behavior in achieving the ideal body with a strict diet. Strict diet which conducted by female adolescent can lead to poor eating habits that ultimately lead to the eating disorder so then can bring negative impact on nutritional status. This study aims to analyze the relation between eating disorder and nutritional status in adolescent female.

Methods : Observational research with cross sectional design was conducted in Modeling Agency Semarang. The sample were 59 members of a modeling agency female adolescentaged 15-19 years that was selected using consecutive sampling method. Assessment of nutritional status was measured by percent body fat with Bioelectrical Impedence Analysis (BIA). Assessment of eating disorderwas obtained by questionnaire Eating Disorder Diagnostic Scale (EDDS). Data was analyzed using chi square test.

Results : This research shows 40 subjects ( $67.8 \%$ ) experienced eating disorder with 11 subject ( 27.5\%) are underfat and 19 subjects ( $32.2 \%$ ) had no eating disorder with normal nutritional status. There is a significant relation of disordered eating and nutritional status value $(p=0: 01 ; p<0.05)$.

Conclusion : Eating disorder was correlated with nutritional status of female adolescent.

Keywords : Eating disorder; nutritional status; agency modeling; female adolescent
\end{abstract}

\section{PENDAHULUAN}

Menurut WHO masa remaja terbagi atas masa remaja awal (early adolescence) berusia 1013 tahun, masa remaja tengah (middle adolescence) berusia 14-16 tahun dan masa remaja akhir (late adolescence) berusia 17-19 tahun. ${ }^{1}$ Adanya berbagai pengaruh dari luar yang rentan dengan mudah diikuti oleh golongan remaja termasuk bagi para remaja putri yang berkecimpung dalam dunia modeling merupakan salah satu populasi yang rentan terhadap terjadinya gangguan makan. Hal tersebut dipengaruhi tuntutan pekerjaan yang mengharuskan mereka memiliki tubuh yang langsing agar terlihat lebih menarik pada saat tampil di depan umum, sehingga tidak sedikit usaha yang dilakukan mereka agar berat badan dan bentuk tubuh tetap terlihat ideal.

Seseorang yang mengalami ketidakpuasan mengenai bentuk tubuh akibat persepsi yang negatif terhadap body image (citra tubuh) akan 
mempengaruhi tindakan seseorang untuk melakukan perilaku makan yang tidak tepat atau diit yang salah, guna mendapatkan bentuk tubuh yang ideal. Keadaan kurang gizi pada remaja sering terjadi akibat dari pembatasan konsumsi makanan dengan tidak memperhatikan kandungan gizi dan kesehatan, sehingga hal tersebut akan berdampak negatif pada status gizi. ${ }^{2}$ Kecemasan akan bentuk tubuh membuat remaja sengaja tidak makan yang berujung pada eating disorder. ${ }^{3}$

Eating disorder adalah gangguan psikologis dan medis yang menyebabkan kelainan serius dalam perilaku makan untuk mengendalikan berat badan atau biasa disebut sebagai suatu gangguan mental yang dapat mempengaruhi remaja. Eating disorder, termasuk anorexia nervosa $(\mathrm{AN})$, bulimia nervosa $(\mathrm{BN})$, binge eating disorder (BED) dan eating disorders not otherwise specified (EDNOS) yaitu menjadi permasalahan yang berhubungan dengan gangguan body image di kalangan remaja. ${ }^{4}$

Hasil penelitian yang membuktikan bahwa dari 61 remaja perempuan pada Modeling School di Jakarta, sebanyak 38 orang $(58.5 \%)$ responden mengalami gangguan makan dengan spesifikasi anorexia nervosa sebanyak 3.1\%, bulimia nervosa $1.5 \%$, binge eating disorder $3.1 \%$ dan eating disorder not otherwise specified (EDNOS) sebanyak $50.8 \%$.

Berdasarkan latar belakang tersebut perlu dilakukan penelitian untuk menganalisis hubungan eating disorder dengan status gizi yang terjadi pada remaja putri di Modeling Agency Semarang. Penelitian dilakukan ditempat tersebut karena dilihat dari letak agency yang berada dipusat kota, dimana para model remaja putri lebih mudah mengakses informasi, mengikuti trend, lebih mudah terpengaruh terhadap fashion dan penilaian terhadap eating disorder. Hal tersebut dapat membuat mereka lebih rentan mengalami eating disorder.

\section{METODE PENELITIAN}

Penelitian ini merupakan penelitian observasional dengan rancangan cross sectional dan termasuk dalam lingkup keilmuan gizi masyarakat. Penelitian dilakukan di Agency Modeling Semarang pada bulan November Desember 2013.

Populasi dalam penelitian ini adalah model remaja putri di Modeling Agency Semarang. Berdasarkan perhitungan menggunakan rumus estimasi proporsi didapatkan subjek minimal 57 subjek dan dalam penelitian ini diperoleh 59 subjek. Metode pengambilan sample menggunakan consecutive sampling, yang sebelumnya telah dipilih sesuai dengan kriteria inklusi yakni model remaja putri usia 15-19 tahun, tidak absen selama pengambilan data, bersedia menjadi responden, dan dapat bekerjasama.

Data yang dikumpulkan dalam penelitian ini adalah karakteristik subjek, eating disorder (variabel bebas) dan status gizi (variabel terikat). Kategori penyimpangan perilaku makan dibagi menjadi empat bagian : 1) Anoreksia nervosa yaitu menurunnya nafsu makan dan ketakutan yang berlebihan pada kenaikan berat badan. 2) Bulimia nervosa yaitu makan berlebihan disertai dengan perasaan dimana penderitanya merasa kehilangan pengendalian diri ketika makan disertai muntah yang dilakukan secara sengaja serta penyalahgunaan obat pencahar dan diuretik. ${ }^{5}$ 3) Binge eating disorder yaitu keadaan mengkonsumsi makanan dalam jumlah banyak dan disertai dengan kehilangan kontrol ketika makan dan terus berulang namun tidak disertai dengan pemuntahan. Setelah makan dalam jumlah yang besar biasanya penderita merasa bersalah dan malu dengan perilakunya. Oleh sebab itu, sebagian besar individu dengan binge eating disorder mengalami obesitas. ${ }^{18}$ 4) Eating disorder not otherwise specified (EDNOS) yaitu seseorang dengan EDNOS merupakan jenis penyimpangan perilaku makan yang lebih ringan dan tidak mempunyai kriteria diagnostik yang spesifik, baik anoreksia maupun bulimia nervosa. Seseorang yang memiliki gangguan makan dengan perilaku makan yang tidak teratur. Penderita EDNOS memiliki gejala yang hampir sama namun tidak seluruhnya menyerupai dengan penderita anoreksia dan bulimia. 19 Data diperoleh dari wawancara langsung menggunakan kuesioner Eating Disorder Diagnostic Scale (EDDS). ${ }^{8}$

Perilaku makan yang tidak baik yang ditunjukkan dengan terpenuhinya salah satu kriteria penyimpangan perilaku makan yang disesuaikan dengan kuesioner. Sedangkan untuk perilaku makan baik tidak terdapat kriteria atau memiliki skor 0 pada kuesioner. Pengkategorian penyimpangan perilaku makan didasarkan pada nilai yang ada dalam kuesioner tersebut. ${ }^{8}$

Pengambilan sampel diawali dengan melakukan pengumpulan data yang meliputi identitas sampel, pengukuran tinggi badan, berat badan dan persen lemak tubuh. Pengukuran tinggi badan menggunakan microtoise dengan ketelitian $0,1 \mathrm{~cm}$. Berat badan diukur menggunakan timbangan digital dengan ketelitian $0,1 \mathrm{~kg}$ dan 
persen lemak tubuh diukur menggunakan Bioelectrical Impedence Analysis (BIA) hasil ukur dinyatakan dalam persentase (\%).

Parameter lain yang digunakan untuk menentukan status gizi adalah persen lemak tubuh. Persen lemak tubuh adalah persentase massa lemak dari total berat badan, hasilnya akan dikonversikan menggunakan persentil lemak tubuh berdasarkan kelompok usia dan jenis kelamin. Persentil dengan kategori underfat adalah persentil $<5$, normal adalah persentil $\geq 5-\leq 85$, overfat adalah persentil $>85-\leq 95$, dan obese adalah $>95$. $^{7}$

Pengolahan dan analisis data dilakukan dengan program komputer. Analisis univariat digunakan untuk menggambarkan karakteristik subjek dan mendeskripsikan masing-masing variabel. Analisis bivariat digunakan untuk mengetahui hubungan antara variable bebas dan terikat dengan uji Chi-square yang sebelumnya dilakukan uji normalitas data dengan uji Kolmogorov-Smirnov. ${ }^{9}$

\section{HASIL PENELITIAN \\ Karakteristik Subjek Penelitian}

Karakteristik subjek penelitian meliputi usia, berat badan, tinggi badan, persen lemak tubuh dan persentil disajikan dalam Tabel 1 .

Tabel.1 Karakteristik Subjek Penelitian

\begin{tabular}{lccccc}
\hline Karakteristik Subjek & Minimum & Maksimum & Rerata \pm SD & Modus & Persentase $(\%$ \\
\hline Usia (Tahun) & 15 & 19 & $17,0 \pm 1.67$ & 19 & 33.9 \\
Berat Badan $(\mathrm{Kg})$ & 37 & 63 & $48.8 \pm 5.28$ & 48 & 8.5 \\
$\begin{array}{l}\text { Tinggi Badan }(\mathrm{cm}) \\
\begin{array}{l}\text { Persen Lemak Tubuh } \\
(\%)\end{array}\end{array}$ & 151 & 173.5 & $163.7 \pm 4.42$ & 165 & 15.3 \\
$\begin{array}{l}\text { Persentil Lemak } \\
\text { Tubuh }\end{array}$ & 2 & 27.80 & $20.5 \pm 3.54$ & - & - \\
\hline
\end{tabular}

Tabel.1 menunjukkan modus pada usia yaitu 19 tahun (33.9\%), berat badan $48 \mathrm{~kg}(8.5 \%)$, tinggi badan $165 \mathrm{~cm}(15.3 \%)$, persentil lemak

\section{Perilaku Makan}

Perilaku makan pada subjek dapat dilihat pada Tabel 2. tubuh $25(40.7 \%)$, sedangkan untuk persen lemak tubuh tidak didapatkan nilai modus.

Tabel 2. Frekuensi distribusi perilaku makan

\begin{tabular}{ccc}
\hline Kategori & Frekuensi & Persentase (\%) \\
\hline $\begin{array}{c}\text { Perilaku makan tidak baik } \\
-\begin{array}{c}\text { Konsumsi obat } \\
\text { berat badan }\end{array}\end{array}$ & 43 & 72.8 \\
$\begin{array}{c}\text { Perilaku makan baik } \\
\text { Total }\end{array}$ & 20 & 33.8 \\
\hline
\end{tabular}

Perilaku makan tidak baik pada penelitian ini sebanyak 43 subjek (72.8\%) dan perilaku makan baik 16 subjek (27.2\%). Sedangkan konsumsi obat-obatan sebanyak 20 subjek (33.8\%)

\section{Eating Disorder}

Berdasarkan wawancara yang mengalami eating disorder dilihat Tabel 3.

Tabel 3. Frekuensi distribusi eating disorder

\begin{tabular}{ccc}
\hline \multicolumn{1}{c}{ Kategori } & Frekuensi & $\begin{array}{c}\text { Persentase } \\
(\boldsymbol{\%})\end{array}$ \\
\hline Eating Disorder & 40 & 67.8 \\
- Anoreksia Nervosa & 5 & 8.5 \\
- Bulimia Nervosa & 14 & 23.7 \\
- Binge Eating Disorder & 4 & 6.8 \\
- eating disorder not otherwise specified & 17 & 28.8 \\
\hline
\end{tabular}




\begin{tabular}{rcc}
\hline Tidak Eating Disorder & 19 & 32.2 \\
\hline Total & $\mathbf{5 9}$ & $\mathbf{1 0 0}$ \\
\hline
\end{tabular}

Penelitian ini menunjukkan sampel yang mengalami eating disorder sebanyak 40 subjek (67.8\%), sedangkan yang tidak mengalami eating disorder 19 subjek (32.2\%). Terdapat subjek yang mengalami anoreksia nervosa 5 subjek $(8.5 \%)$, bulimia nervosa 14 subjek (23.7\%), binge eating disorder 4 subjek (6.8\%), eating disorder not otherwise specified (EDNOS) 17 subjek (28.8\%), sedangkan untuk normal sebanyak 19 subjek $(32.2 \%)$.

\section{Status Gizi}

Distribusi frekuensi status gizi pada subjek penelitian dilihat dalam Tabel 4 .

Tabel 4. Distribusi frekuensi status gizi

\begin{tabular}{lccc}
\hline & Kategori & Frekuensi & Persentase (\%) \\
\hline Underfat & 11 & 18.6 \\
Normal & 48 & 81.4 \\
Overfat & - & - \\
Obesitas & - & - \\
& & & $\mathbf{1 0 0}$ \\
\hline
\end{tabular}

Status gizi pada subjek penelitian yang mengalami underfat 11 subjek (18.6\%) dan normal 48 subjek (81.4\%), sedangkan untuk overfat dan obesitas tidak ditemukan subjek dalam penelitian.

\section{Hubungan Eating Disorder dengan Status Gizi} Hubungan antara eating disorder dengan status gizi pada remaja putri dapat dilihat pada tabel 5 .

Tabel 5. Hubungan eating disorder dengan status gizi

\begin{tabular}{|c|c|c|c|c|c|}
\hline \multirow{3}{*}{ Variabel } & \multicolumn{4}{|c|}{ Status Gizi } & \multirow{3}{*}{$p^{a}$} \\
\hline & \multicolumn{2}{|c|}{ Underfat } & \multicolumn{2}{|c|}{ Normal } & \\
\hline & $\mathbf{n}$ & $\%$ & $\mathbf{n}$ & $\%$ & \\
\hline Tidak Eating Disorder & 0 & 0 & 19 & 100 & \\
\hline Eating Disorder & 11 & 27,5 & 29 & 72,5 & 0,011 \\
\hline Total & 11 & 18,6 & 48 & 81,4 & \\
\hline
\end{tabular}

\section{Keterangan a: Fisher's Exact Test}

Hasil analisis diperoleh ada hubungan antara eating disorder dengan status gizi $(p=0,011)$. Penelitian ini menunjukkan bahwa terdapat hubungan yang bermakna antara eating disorder dengan kejadian status gizi nilai $(p<0,05)$.

\section{PEMBAHAHASAN}

Subjek dalam penelitian ini berusia 15-19 tahun, dengan usia rata-rata 17 tahun sedangkan frekuensi terbesar yaitu usia 19 tahun sebanyak 20 subjek (33.9\%). Pada rentang usia tersebut, remaja umumnya mulai memperhatikan dan membandingkan hal-hal khusus seperti penampilan fisik (misalnya bentuk tubuh) dan kemampuan sosial dengan lingkungan pergaulannya. Remaja menyadari bahwa daya tarik fisik berperan penting dalam hubungan sosial. Hal tersebut menyebabkan remaja sangat terpengaruh pada penilaian orang lain terhadap bentuk tubuhnya. ${ }^{10}$ Pada usia remaja banyak dari mereka yang mengubah penampilannya agar terlihat menarik. Kepedulian terhadap penampilan dan gambaran tubuh yang ideal dapat mengarah pada upaya obsesif seperti mengontrol berat badan. ${ }^{11}$

Bagi remaja yang sudah memiliki profesi sebagai model rentan mengalami eating disorder karena seorang model perlu menjaga bentuk tubuhnya agar terlihat menarik di hadapan orang lain. Persepsi body image yang negatif akan mempengaruhi seseorang untuk melakukan upaya pengurangan konsumsi makanan. Keinginan untuk memiliki bentuk tubuh yang sempurna dan 
persaingan di dunia model yang ketat membuat para model tersebut melakukan apa saja agar bentuk tubuh mereka menjadi sempurna, salah satunya adalah dengan melakukan diet ketat. Diet ketat yang dilakukan para model lama-kelamaan membawa pada kebiasaan makan yang kurang baik yang pada akhirnya menyebabkan terjadinya gangguan makan atau eating disorder. ${ }^{12}$

Kejadian eating disorder di kalangan remaja salah satu faktor penyebabnya yaitu body image negatif. Sesorang yang memiliki body image negatif cenderung melakukan perilaku makan yang tidak baik. Perilaku makan tidak baik yang dilakukan remaja dalam penelitian ini sebanyak 43 subjek $(72.8 \%)$ yaitu makan tidak teratur atau sering melewatkan waktu makan tertentu, misalnya sering melewatkan makan pagi karena malas atau tidak ada waktu dan makan malam karena takut menjadi gemuk. Sedangkan remaja yang menggunakan obat pelangsing, obat pencahar atau obat penurun berat badan untuk mencegah kenaikan berat badan ada 20 subjek (33.8\%).

Sebagian besar remaja putri dalam penelitian ini belum menjalankan perilaku makan yang baik. Berdasarkan hasil wawancara menggunakan kuesioner yang di adopsi dari Eating Disorder Diagnostic Scale diketahui bahwa sebanyak 40 subjek (67.8\%) mengalami eating disorder, sedangkan yang tidak mengalami eating disorder 19 subjek (32.2\%). Penelitian lain juga menunjukkan adanya gangguan makan pada remaja putri di modeling school Bogor pada tahun 2012 dari 50 responden, 25 subjek (25\%) mengalami gangguan makan dan 25 subjek $(25 \%)$ normal. ${ }^{14}$

Sebagian besar remaja putri pada penelitian ini menurut kategori eating disorder yaitu terdapat 19 subjek (32.2\%) normal, 5 subjek $(8.5 \%)$ anoreksia nervosa, 14 subjek (23.7\%) bulimia nervosa, binge eating disorder 4 subjek $(6.8 \%)$ dan EDNOS 17 subjek (28.8\%). Hasil ini sejalan dengan penelitian di Jakarta tahun 2009 pada 61 remaja perempuan Modeling School di Jakarta, sebanyak 38 orang $(58.5 \%)$ responden mengalami gangguan makan dengan spesifikasi anorexia nervosa sebanyak $3.1 \%$, bulimia nervosa $1.5 \%$,binge eating disorder $3.1 \%$ dan eating disorder not otherwise specified (EDNOS) sebanyak $50.8 \% .^{6}$

Pada umumnya seseorang yang termasuk dalam penderita eating disorder adalah orangorang yang memiliki kepercayaan diri yang rendah dan perasaan tidak sebanding dengan orang lain bahwa menganggap dirinya memiliki tubuh yang gemuk sedangkan orang lain memiliki tubuh yang ideal. Banyak dari mereka berpikir bahwa makanan adalah sumber kenyamanan atau penghilang stress sementara penurunan berat badan dianggap sebagai cara agar diterima oleh temanteman dan keluarga. ${ }^{6}$ Hingga akhirnya eating disorder mempengaruhi status gizi mereka.

Pengukuran persen lemak tubuh untuk mengetahui status gizi diperlukan untuk melihat komposisi lemak tubuh pada remaja putri. ${ }^{20}$ Berdasarkan persen lemak tubuh kategori underfat yaitu ditemukan sebanyak 11 subjek (18.6\%), kategori normal yaitu sebanyak 48 subjek (81.4\%). Pada penelitian ini ditemukan 11 subjek kategori underfat yang mengalami eating disorder.

Keadaan kurang gizi pada remaja sering terjadi akibat dari pembatasan konsumsi makanan dengan tidak memperhatikan kandungan gizi dan kesehatan, sehingga hal tersebut akan berdampak negatif pada status gizi. ${ }^{2}$ Didapatkan bahwa responden yang berstatus gizi normal lebih banyak $(81.4 \%)$ dibandingkan yang berstatus gizi kurang $(18.6 \%)$. Hal ini sejalan oleh data dari Riset Kesehatan Dasar tahun 2010 yang menyatakan bahwa prevalensi status gizi normal untuk usia remaja di wilayah Jawa Tengah sebesar 91\%. Hal ini memperkuat bahwa tingkat status gizi normal di modeling agency Semarang berada dalam prevalensi normal yang ada di Jawa Tengah. ${ }^{15}$ Meskipun diketahui sebanyak 48 subjek $(81.4 \%)$ berstatus gizi normal, namun terdapat 29 subjek $(60.5 \%)$ diantaranya termasuk dalam kategori eating disorder dan hanya 19 subjek (39.5\%) tidak termasuk dalam eating disorder yang berstatus gizi normal.

Seseorang yang mengalami ketidakpuasan mengenai bentuk tubuh akibat persepsi yang negatif terhadap body image akan mempengaruhi tindakan seseorang untuk melakukan perilaku makan yang tidak tepat, guna mendapatkan bentuk tubuh yang ideal. Terbentuknya konsep diri berupa body image pada remaja merupakan salah satu faktor dampak pada status gizi yang menyebabkan kebanyakan remaja kekurangan asupan makanan karena melakukan diit yang salah. ${ }^{16}$ Kecemasan akan bentuk tubuh membuat remaja sengaja tidak makan yang berujung pada eating disorder. ${ }^{3} \mathrm{Hal}$ ini diperkuat oleh teori yang menyatakan bahwa faktor risiko dari eating disorder yang meliputi body image atau ketidakpuasan terhadap bentuk tubuh, pengaruh media, pengetahuan yang kurang dan perilaku seperti diet yang terlalu ketat, perhatian berlebih terhadap berat badan, hal 
tersebut yang dapat mempengaruhi hubungan antara perilaku makan dengan status gizi. ${ }^{17}$

Hasil analisis bivariat diperoleh adanya hubungan eating disorder dengan status gizi remaja putri $(p=0.011)$. Penelitian ini menunjukkan bahwa terdapat hubungan yang bermakna antara eating disorder dengan kejadian status gizi $(\mathrm{p}<0.05)$. Hal tersebut sesuai teori yang mengemukakan bahwa lingkungan, keluarga, teman sebaya, individu, gaya hidup dan body image yang dapat mempengaruhi sesorang untuk merubah perilaku makan mereka sehingga berdampak pada status gizi. ${ }^{13}$

\section{SIMPULAN}

Eating disorder mempunyai hubungan yang bermakna dengan status gizi pada remaja putri.

\section{SARAN}

Bagi remaja putri yang memiliki ketidakpuasan terhadap body image perlu adanya bimbingan dan arahan dari pihak keluarga, khususnya dalam hal perilaku makan yang akan menyebabkan terjadinya eating disorder sehingga tidak menimbulkan masalah gizi. Bagi remaja putri yang tidak mengalami eating disorder diharapkan mampu menjaga perilaku makannya dan memiliki kepuasan terhadap body image. Untuk penelitian lebih lanjut yang berkaitan dengan eating disorder, disarankan untuk dilakukan secara langsung yaitu dengan mengobservasi perilaku makan responden serta menganalisis asupan makan secara kuantitatif.

\section{DAFTAR PUSTAKA}

1. Tarwoto, Aryani R, Nuraeni A, Miradwiyana B, Nurbayani S. Kesehatan Remaja Problem dan Solusinya. Jakarta : Salemba Medika. 2010 ; 2528.

2. Kusumajaya NA, Wiardani NK, dan Juniarsana IW. Persepsi Remaja terhadap Body Image Kaitannya dengan Pola Konsumsi Makan. Jurnal Skala Husada. Vol 5/2. 2008 : 114-125

3. Kjelsa's, Einar, Christian Bjørnstrøm, K. Gunnar Go"testam. Prevalence of eating disorders in female and male adolescents (14-15 years). Elsevier. Eating Behaviors. 2004;13-25.

4. Naomi C, Jennifer A. O'Dea. Body image and eating disorders amongst Japanese adolescents. A review of the literature. Elsevier. Sydney, Australia. 2009;5-7.

5. Chavez, M., Insel, T.R. Eating Disorders: National Institute of Mental Health's Perspective. American Psychology ; 2007. 62(3): 159-166.
6. Hapsari I. Perilaku Makan Menyimpang pada Remaja di Jakarta (Skripsi). Program Sarjana FKM UI. 2009.

7. World Health Organization (WHO). Growth References 5-19 years for Adolescent. Diunduh dari http://www.who.int//growthreferences519 yearsforadolescent.2007-pdf//.

8. Roberts, Bonnie S. Nutrition Throughout The Life Cycle. Singapore : Mc Graw-Hill. 2000 ; 255.

9. Garwati A, Wijayati I. Goodbye Lemak 3 Langkah Mudah Membentuk Tubuh Ideal. Jakarta:Gelanggang press. $2010 ; 10-15$.

10. Rice, F. Philip. The adolescent ( $6^{\text {th }}$ edition). USA : Ally \& Bacon. $1990 ; 120$.

11. Papalia, D. E, Olds, S. W. \& Feldman, R. D. Human development (Psikologi perkembangan edisi kesembilan). Jakarta. 2008 ; 50.

12. Henry \& Lori. Ana Carolina Reston Dies ; 2006 . from www.suite101.com

13. Stang J, Story M. Guidelines for adolescents nutrition services; $2005 . \quad$ From http://www.epi.umn.edu/let/pubs/adol_book.shtm

14. Purba, Ria Natalia. Faktor-Faktor yang Berhubungan dengan Gangguan Makan pada Remaja Perempuan Di Modeling School (Skripsi). Institiut Pertanian Bogor. 2012 ; 13-17.

15. Riset Kesehatan Dasar. Status Gizi Remaja Umur 16-18 Tahun (IMT/U). 2010.

16. Istiono W, Suryadi H, Haris M, Irnizarifka. Analisis Faktor-Faktor yang Mempengaruhi Status Gizi. Berita Kedokteran Masyarakat. 2009. Vol. 25 no. $3 ; 225$.

17. J. Worobey, B. J. Tepper and R. B. Kanarek. Nutrition and Behavior : A Multidisciplinary Approach $2006 ; 546$.

18. Latner JD, Wilson GT. Binge Eating and Satiety in Bulimia Nervosa and Binge Eating Disorder: Effects of Macronutrient Intake. Graduate School of Applied and Professional Psychology. Rutgers University ; 2004. 36 : 402-415 http://www2.hawaii.edu/ jlatner/downloads/pubs/I JEDpaper.pdf.

19. American Psychiatric Association : The Diagnostic And Statistical Manual of Mental Disorder's, $4^{\text {th }}$, edition. Text Revision. 2000 ; 345.

20. Suandi KG, Soetjiningsih, IBCLC. Tumbuh Kembang Remaja dan Permasalahannya. Jakarta :Sagung Seto. 2004 ; 23. 